\title{
Comments surrounding the doctor of nursing practice (DNP): Stress, ambiguity, and strain
}

\author{
Josephine M. Mancuso ${ }^{* 1}$, Kimberly A. Udlis ${ }^{2}$, Allison B. Anbari ${ }^{3}$ \\ ${ }^{1}$ College of Nursing, Marquette University, Milwaukee, WI, United States \\ ${ }^{2}$ Bellin College, Green Bay, WI, United States \\ ${ }^{3}$ School of Nursing, Missouri State University, Springfield, MO, United States
}

Received: September 6, 2016

DOI: $10.5430 /$ jnep.v7n4p76
Accepted: November 13, 2016 Online Published: November 29, 2016

URL: http://dx.doi.org/10.5430/jnep.v7n4p76

\begin{abstract}
Background/Objective: The Doctor of Nursing Practice (DNP) degree is the recommended preparation for advanced nursing practice. However, lack of clarity surrounding the DNP degree has contributed to role ambiguity for the DNP prepared nurse. The present study sought to evaluate the written comments obtained from a quantitative analysis that utilized a framework adapted from works on role conflict and ambiguity, role stress and strain, and classical organization theory.

Methods: The sample consisted of 113 participant comments. The length of the comments ranged from 1 to 28 lines. Content analysis was performed and the areas of role stress, ambiguity, and strain were identified.

Results: Distinct areas for intervention to address DNP role stress and strain with the goal of preventing the harmful outcomes of role ambiguity were identified. For example, comments centered along the lines that the benefits of pursuing a DNP degree did not outweigh costs. There is contention among PhD, DNP, and MSN prepared nurses. The DNP causes role confusion among health care providers and the public and conflict exists about the DNP role and professionalism, faculty preparation, and leadership.

Conclusions: The authors provide several recommendations that can reduce role stress, strain, and ambiguity in order to meet the ultimate goal of achieving improved patient/population and policy outcomes. The nursing profession must not only articulate clear and distinct intended outcomes of the DNP degree, but then must also assure that the product of the DNP degree is consistent with those outcomes.
\end{abstract}

Key Words: Doctor of Nursing Practice (DNP), DNP Role, Stress

\section{INTRODUCTION}

There are now two distinct doctoral degrees in nursing: the $\mathrm{PhD}$ (doctor of philosophy) and the DNP (doctor of nursing practice). The two doctoral degrees are meant to complement each other, one for research $(\mathrm{PhD})$ and one for practice (DNP), and to maintain a commitment to advance the nursing profession and pursue scholarly excellence within the discipline ${ }^{[1]}$ Nevertheless, there is a lack of clarity related to the objectives, competencies, and outcomes of the different doctoral degrees. ${ }^{[2]}$ Since 1970, the $\mathrm{PhD}$ in nursing has been widely accepted as a research doctorate and understood as the highest degree and attainment of scholarship of the nursing profession. ${ }^{[3]}$ The DNP degree is the recommended preparation for advanced nursing practice which includes both indirect and direct nursing care roles. Examples of indirect care areas are nursing administration and leadership, health policy, informatics, and population health. There are four direct care areas or roles, all considered advanced practice registered nurses (APRN): certified nurse-midwife (CNM), certified registered nurse anesthetist (CRNA), clinical nurse

*Correspondence: Josephine M. Mancuso; Email: josephine.mancuso@marquette.edu; Address: College of Nursing, Marquette University, Milwaukee, WI, United States. 
specialist (CNS), and nurse practitioner (NP). ${ }^{[1,4]}$

Support for the value of the DNP degree has resulted in rapid proliferation of DNP programs over a relatively short period of time. ${ }^{[4]}$ However, issues regarding DNP program variability in terms of length, program focus, DNP project/scholarly project/capstone, rigor, and number of credits have been reported. ${ }^{[5,6]}$ In the academic setting, recent DNP graduates have identified role strain and stress surrounding faculty expectations, preparation, and support. ${ }^{[2]}$ Despite the exponential growth of DNP programs (20 in 2006 to 264 in 2014), the complete transition to the DNP degree for APRNs is still evolving, and the majority of programs continue to prepare APRNs at the master's level (masters of science in nursing $[\mathrm{MSN}]) \cdot{ }^{[4,7,8]}$

With two terminal nursing degrees, multiple entries to APRN preparation, DNP program variability, and doctoral programs developing at an unprecedented rate, lack of role clarity and increased role ambiguity have surfaced. While it is understood that the DNP is an academic degree and not a role, DNP graduates will ultimately fulfill various roles within the nursing profession and society. Role ambiguity does not only potentially result in dissatisfaction and uncertainty for the DNP prepared nurse, but can also ripple outward to create confusion for the nursing profession and for other healthcare colleagues. Transitional stress and strain are natural and arguably expected with any change, particularly one as significant as a new doctoral degree in the profession. However, DNP role ambiguity, if left unattended and unaddressed, may result in adverse consequences and thus jeopardize the actualization of this practice doctorate in nursing.

\subsection{Clarity or confusion}

Multiple publications from nursing organizations have attempted to deliver a clear and consistent message regarding the intended goals and outcomes of the DNP. ${ }^{[1,4,9-12]}$ Nurse leaders have articulated the potential and actual confusion related to understanding the DNP degree and differentiation from other advanced nursing degrees. ${ }^{[10,13,14]}$ Yet, the operationalization of the DNP degree has been less than clear and consistent. Unease and uncertainty may occur with any new degree requirement, however, ongoing lack of role clarity may result in negative outcomes.

Collaboration between $\mathrm{PhD}$ and DNP prepared nurses has been proposed as a means to improving healthcare, developing a reciprocal relationship between practice driving research and research driving practice. ${ }^{[15-17]}$ However, the lack of role clarity and the presence of role ambiguity between the $\mathrm{PhD}$ and DNP degrees are prevalent. ${ }^{[18-20]}$ This lack of role clarity threatens the goal of PhD-DNP collaboration because Published by Sciedu Press interprofessional collaboration requires an understanding of the roles of other members of the health care team. ${ }^{[21]}$

Lack of role clarity may also be the impetus for people questioning the necessity and feasibility of the DNP degree. Chief nursing officers (CNOs) have been shown to agree that the DNP degree provides nurse executives with knowledge to impact business operations, nursing retention, patient care, implementation of nursing research, and health policy. ${ }^{[22]}$ However, in the same study, CNOs disagreed with endorsing the DNP degree as the recommended advanced degree for nurse executives. Another survey of CNOs in the Midwest showed that less than half $(41 \%)(n=17)$ reported employing DNP prepared nurses. Furthermore, the CNOs who completed the survey lacked knowledge of actual DNP practice and its potential impact on outcomes. ${ }^{[23]}$ Another group of community and public health nurse leaders felt that there were few advantages to the DNP degree in their setting and that awareness of the DNP among their practice colleagues was minimal. In addition, these nurse leaders were not sure how the DNP would have any additional value over a doctor of public health, which is a more recognized doctorate in the public health setting. [24]

The MSN-prepared APRN is well-supported as a quality and safe provider of direct patient care while the DNP degree has been perceived to be more a costly and burdensome preparation for APRNs. ${ }^{[25]}$ In addition, it has been argued that the type of degree (DNP or MSN) does not impact the marketability of nurse practitioners. ${ }^{[26]}$ Many master's prepared nurses may be wondering why they need a DNP degree when they have been successfully practicing with their current academic preparation. APRNs will be educated at both the MSN and DNP level in the foreseeable future, and thus, both types of APRNs will continue to practice side by side. ${ }^{[7]}$ The recent RAND report, The DNP by 2015, revealed that the master's in nursing (MSN) remains the most common educational preparation for APRNs across programs. Furthermore, 65\% of schools that do offer the BSN-to-DNP degree continue to confer an MSN along the way. ${ }^{[7]}$ APRNs prepared at the master's level have a vast array of evidence to support their contributions, improved access to care, quality of care, and safe care in the healthcare environment. ${ }^{[27,28]}$ Strain between MSN and DNP prepared APRNs has the potential to negatively impact the successful incorporation of the DNP degree into the APRN profession.

\subsection{Conceptual framework}

The framework guiding this research was adapted from the works of Rizzo et al. (1970) and Hardy et al. (1988). ${ }^{[29,30]}$ Rizzo et al. focused on the principles of unity and chain of command to deter role conflict and ambiguity. ${ }^{[29]}$ Hardy 
et al. (1988) examined how rapid changes in organizations and accelerated technology contributed to role stress and strain which can prevent goal attainment for organizations and its members. ${ }^{[30]}$ The AACN, as a leading nursing organization, has recommended the DNP be the terminal degree for all advanced nursing practice by 2015 to improve patient, population, and policy outcomes. ${ }^{[9]}$

A role is defined as a set of obligations, demands, and behaviors associated with a position. ${ }^{[29,31]}$ When expectations and values about the role are not met, role stress ensues. Role stress is a sense of awareness that causes feelings of conflict, distress, and irritation when role obligations are vague and difficult to meet. Role stress is external to the individual; it is inherent to the organization and is most prevalent in the form of role ambiguity among nurses. ${ }^{[31]}$ Operationally, role ambiguity is defined as an absence of clarity regarding one's responsibilities and expectations. ${ }^{[31]}$ Role ambiguity may conceivably foster dissatisfaction and uncertainty, ${ }^{[29]}$ and leads to role strain or feelings of tension, anxiety, or frustration surrounding the role. ${ }^{[31]}$ Role strain is more personal than role stress and promotes ineffectiveness and impedes goal attainment. Role stress, ambiguity, and strain are reciprocal and interrelated.

\section{Methods}

\subsection{Aim}

This study sought to evaluate the written comments obtained from the quantitative study: "Perceptions of the Role of the DNP Prepared Nurse: Clarity or Confusion" "[19] which explored how nurses perceived the various roles of the DNP prepared nurse. Using the comments obtained at the end of the questionnaire, the current study aims to answer the question: Are areas of role stress, ambiguity, and strain present? The quantitative results, generated from a questionnaire, revealed that nurses valued the DNP degree and its contributions to advancing healthcare outcomes through nursing leadership, policy, evidence-based practice and interprofessional collaboration. However, areas of ambiguity were identified in the questionnaire items regarding nursing research, academia, academic leadership and scholarship. In addition, statistically significant differences were present in perceptions of DNP roles across participants' levels of education (PhD, DNP and MSN). ${ }^{[19]}$

\subsection{Design}

The full questionnaire development, reliability and validity information, as well as results can be found in the initial article. ${ }^{[19]}$ A researcher-developed 20-item questionnaire was distributed on-site at two large Midwestern United States nursing conferences in the spring of 2013. In addition, there was an option to complete the same questionnaire online. The first conference site was a four day research conference that attracted a majority of $\mathrm{PhD}$ prepared, academic-research focused nurses. The second conference site was a three day pharmacology conference attended primarily by masters prepared advanced practice nurses. The goal of administering the questionnaire in these two settings was to obtain a convenience sample representative of nursing in the areas of scholarship, academia, and practice. All persons in attendance of the conferences who identified themselves as nurses with at minimum a Bachelor of Science in nursing degree were eligible to participate.

The questionnaire included a single line at the end with the header: Comments. The comment line was included to obtain complementary data and allow participants to expand their thoughts into words. Comment sections and openended questions are often included in questionnaires so that participants can briefly share experiences and personal information, comment on the survey itself, and qualify their responses. ${ }^{[32,33]}$ The analysis of the comments aimed to further assess nurses' ideas about the DNP prepared nurse and to examine the comments for areas of role stress, strain, and ambiguity.

\subsection{Sample}

One hundred twenty-one of the 340 (35.5\%) participants included written comments. Of these 121, eight participants only addressed the survey design without commenting on the DNP degree or role and were not used in analysis. Therefore, 113 participant comments were included in the final content analysis. The sample was predominately white females $(93.8 \%)$ with a mean age of 51 . The majority of participants were master's prepared (60\%), 29\% were PhD-prepared, $8 \%$ were DNP prepared, and 3\% were BSN-prepared. A third of the sample (33\%) identified themselves as faculty with an average of 12 years in the faculty role. The distribution of degree level across those who were in the faculty role were: $62 \% \mathrm{PhD}, 8 \% \mathrm{DNP}$, and $30 \% \mathrm{MSN}$. Just over $70 \%$ of the sample listed clinical practice as their main practice setting with $70 \%$ of this group identifying themselves as APRNs. The distribution of degree level across those who were in the clinical practice role was: $16 \% \mathrm{PhD}, 9 \% \mathrm{DNP}, 71 \% \mathrm{MSN}$, and $4 \%$ BSN. Almost $5 \%$ of the sample identified their practice settings as both faculty and clinical. The nursing education mix of this qualitative sample closely resembled the education mix of the quantitative sample. Furthermore, this sample represented nurses who have DNP degrees and those nurses who reasonably should be expected to have knowledge of the DNP degree. The length of the comments ranged from 1 to 28 lines. 


\subsection{Analysis}

A document of the 113 participant comments was read and memos were taken in the margins. To decrease bias, participant numbers were the only identifiers used to separate comments, i.e. the participants' nursing degrees and background were unknown during this analysis. The document was then uploaded to the online qualitative analysis software Dedoose and content analysis was used to identify reoccurring areas in the participants' comments. Content analysis is often used to identify trends or test existing theories and therefore was well-suited for working with this type of data. ${ }^{[34,35]}$ Participant comments and portions of their comments were divided, sorted, and labeled using open coding techniques. If a participant commented, for instance, on the DNP degree as being confusing as well as costly, the comment was broken down into two parts and coded accordingly. At first, the codes were given broad titles and loose definitions and then narrowed as analysis continued. For example, the code name Confusion was used only until it became evident that participants were commenting more specifically about who might be confused by the DNP degree. This code name was then broken down into several different Confusion codes.

Initial code titles and the frequency of comments within those codes were identified by author 1 . The code titles were discussed and verified by authors 2 and 3 . Each code title and the excerpt within that title were then examined by all three team members for fit within the pieces of the Role Stress, Ambiguity, and Strain framework. The original figure from Udlis and Mancuso ${ }^{[19]}$ was updated to incorporate the qualitative findings (see Figure 1). Code titles and excerpt counts within the areas of role stress, ambiguity, and strain were also identified within the participants' comments as seen in Table 1.

\section{Results}

Participants frequently chose to write about what they thought the differences in the DNP and PhD degrees and roles were. Twenty-four participants wrote in goal oriented or qualifying comments similar to "... The DNP should be the practice/research degree and the $\mathrm{PhD}$ should be the research/education degree," and "PhD - prepares a scientist and leader. DNP - prepares advanced practice leader that incorporates data into daily critical thinking and decision making." Areas of role stress, ambiguity, and strain were also identified within the participants' comments as seen in Table 1. The comments supported and expanded the original framework presented in Udlis and Mancuso. ${ }^{[19]}$ Using the comments, we were able to identify that both role ambiguity and role strain have the potential to inhibit goal attainment (see Figure 1). Furthermore, the comments allowed us to identify more specific areas of stress, strain, and ambiguity and to move forward with a discussion regarding areas of intervention.

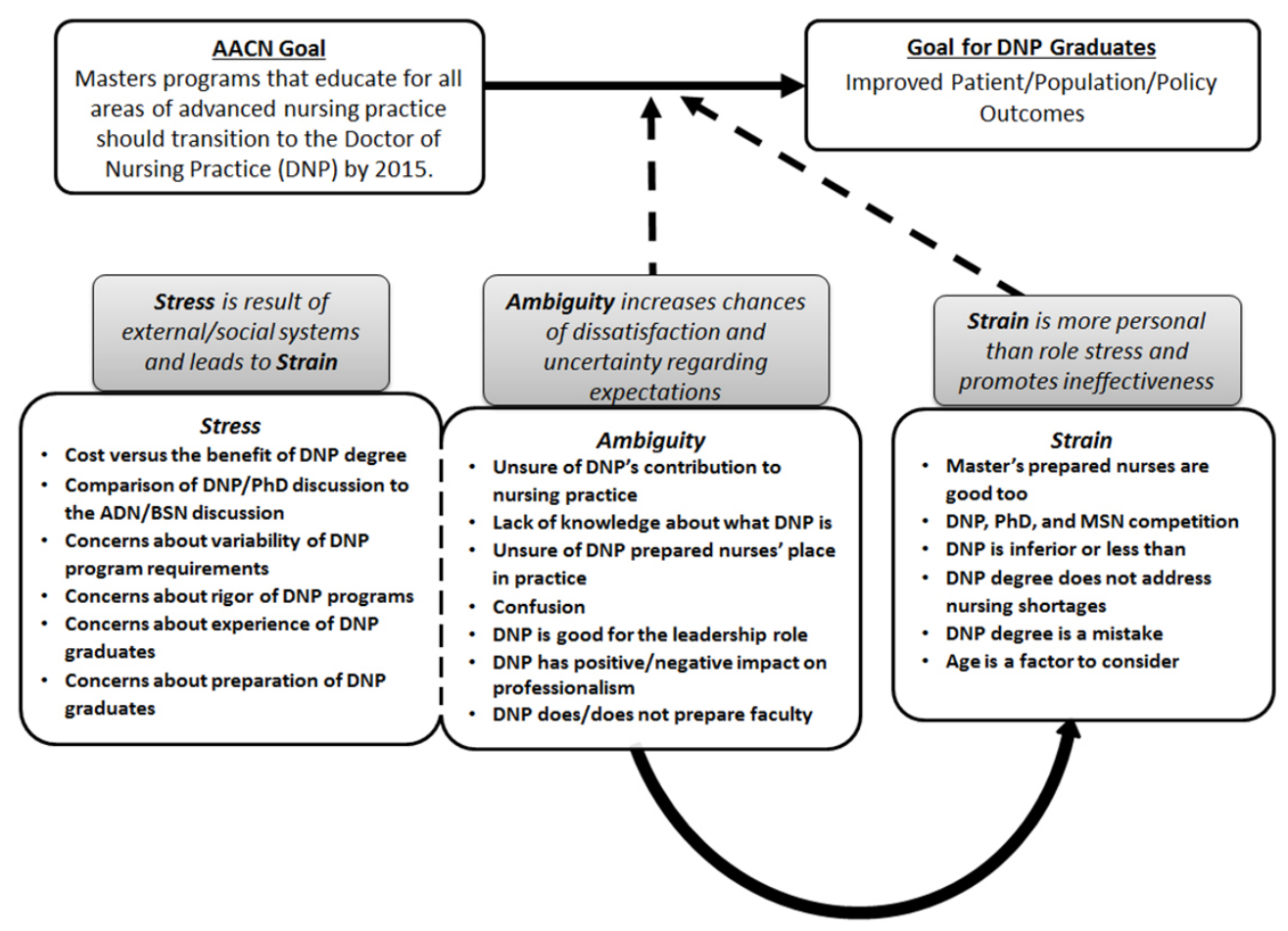

Figure 1. Role stress, ambiguity, and strain framework with qualitative findings 
Table 1. Code titles and excerpt counts within the framework

\begin{tabular}{|c|c|c|}
\hline Framework Area & Code Titles & Participants Excerpt Counts \\
\hline \multirow{6}{*}{ Stress } & Cost versus the benefit of DNP Degree & 23 \\
\hline & Comparison of $\mathrm{DNP} / \mathrm{PhD}$ discussion to the $\mathrm{ADN} / \mathrm{BSN}$ discussion & 11 \\
\hline & Concerns about variability of DNP program requirements & 11 \\
\hline & Concerns about rigor of DNP programs & 10 \\
\hline & Concerns about experience of DNP graduates & 8 \\
\hline & Concerns about preparation of DNP graduates & 4 \\
\hline \multirow{12}{*}{ Ambiguity } & Unsure of DNP's contribution to nursing practice & 19 \\
\hline & Lack of knowledge about what DNP is & 18 \\
\hline & Unsure of DNP prepared nurses’ place in practice & 9 \\
\hline & Confusion (other healthcare providers) & 9 \\
\hline & Confusion (nurses) & 8 \\
\hline & Confusion (public) & 7 \\
\hline & Confusion (not specified/general) & 7 \\
\hline & DNP is good for the leadership role & 6 \\
\hline & DNP has positive impact on professionalism* & 5 \\
\hline & DNP has negative impact on professionalism* & 4 \\
\hline & DNP does prepare faculty* & 3 \\
\hline & DNP does not prepare faculty* & 6 \\
\hline \multirow{6}{*}{ Strain } & Master's prepared nurses are good too & 16 \\
\hline & DNP, PhD, and MSN competition & 10 \\
\hline & DNP is inferior or less than... & 6 \\
\hline & DNP degree does not address nursing shortages & 5 \\
\hline & DNP degree is a mistake & 5 \\
\hline & Age is a factor to consider & 4 \\
\hline
\end{tabular}

*Indicates paired code titles that contribute to ambiguity

\subsection{Role stress}

Areas of role stress were identified in the participants' comments. Participants cited uncertainty that the benefits of pursuing a DNP degree outweighed the costs. They also frequently compared the $\mathrm{DNP}$ and $\mathrm{PhD}$ discussions to that of the ongoing Associate degree versus bachelor's degree in nursing discussions with comments such as, "I believe that the nursing profession continue [s] to look at the wrong end of entry into practice."

Another participant wrote:

"There is still a lot of education to be done in and out of nursing as to what the DNP offers to practice. I do think eventually employers will prefer DNPs just as many are starting to prefer BSNs (RN) to other nursing degrees for entry level nursing."

Another form of role stress was found in participants questioning the rigor and large variability of DNP programs and concerns that the experience and preparation of DNP prepared nurses when they enter the workforce. One participant commented:
"In my experience, the DNP program is less rigorous than the PhD or DNSc. The DNP is really a 'glorified' MSN. The emphasis is EBP, rather than research. I think it's a 'quick fix' and the easy way to be 'called' Dr. but the program lacks substance. DNPs make a mockery of 'PhDs/DNSc'."

Similarly, another participant wrote:

"There may be potential for our DNP grads to be better prepared, but currently they are often primarily focused on becoming APRNs, not doctorally prepared clinicians. The programs are rushed, the students are often young and poorly prepared as leaders when they finish. We are trying to prepare too many students at the DNP level to be successful..."

\subsection{Role ambiguity}

Overwhelmingly, participants mentioned the DNP degree as causing confusion. Confusion for other nurses, other healthcare providers, and confusion to the general public were 
mentioned 31 times in comments such as this participant who cites the various sources of confusion.

"While I support the role of the DNP, I am becoming disheartened with the bigger picture of nursing. When will we be our own identity and stop trying to compete with other professions. We are confused with our own identity as nursesI fear that we have so many roles/degrees that not only is it confusing for other healthcare professionals, it is for us as 'nurses'. We are slowly eliminating 'who we are' because there are too many nursing degrees. Lay people still have a hard time understanding RN and BSN now add more confusion with the DNP and PhD."

Likewise another participant wrote,

"I feel the DNP has muddied the picture in the nursing profession. $\mathrm{A} \mathrm{PhD}$ is already a terminal degree. A DNP is confusing to patients, other APN, nurses, and physician colleagues."

Participants also admitted to a lack of knowledge about the DNP degree. Comments such as:

"More education is needed to educate practicing APRN's regarding the goal, purpose, benefits of the DNP role. How does the DNP change practice? What is the DNP role? What can a DNP do that a MSN prepared APRN can't do?"

and

“... I do not truly know the difference between PhD and DNP nurses" demonstrated that even nurses attending research and clinical conferences still did not fully understand the DNP degree and role.

Participants were also concerned about how the DNP degree contributes to nursing practice and patient outcomes and were unsure of the DNP prepared nurse's place in practice. “... We still are not nurses or physicians. Lost in the middle yet..."

Another participant wrote,

"Employers (and potential DNP students) do not really know or understand the benefit of the degree and how it will impact their clinical practice, salaries, etc."

Ambiguity regarding the DNP degree and role was also evident in conflicting code categories. For example, participants commented that the DNP degree does not prepare nurses for

Published by Sciedu Press leadership positions, faculty roles, nor adds to nursing professionalism, while other participants commented the exact opposite, praising the degree and its value. Comments such as "Having [two] separate terminal degrees is harming the profession" were at odds with comments such as "I believe the 'Dr' title will add more in practice by bringing us up to other allied health professions... and allows us to develop different roles..."

\subsection{Role strain}

Areas of role strain also were identified in the participants' comments. Comments within this portion of the framework were wrought with contention, including frequent comments about the MSN prepared nurse being good too or that adding the DNP was a mistake. One participant commented,

"Pushing all of us who have master's to get a DNP is rather annoying and insulting... I don't get to do anything extra in regards to role, practice, prescribing."

Another wrote:

"I cannot believe that having a DNP will improve the quality of patient care. I believe that all levels of nursing improve safe nursing care. NPs [nurse practitioners] have been master's prepared for years and have practiced keeping patients safe..."

Participants also commented that the DNP degree does nothing to address nursing shortages.

"I don't feel the DNP role effectively responds to the health care needs and shortages for nursing need to develop more practitioners researchers and academics."

Other areas of role strain were evident in participants' comments about the DNP degree being inferior or that the three graduate nursing degrees, MSN, PhD, and DNP, were in some way competing with each other.

"It is imperative that DNP programs do not seriously compromise the $\mathrm{PhD}$ programs..."

Another participant wrote:

"The DNP and PhD are not equitable. If DNP graduate faculty are held to $\mathrm{PhD}$ standards, they will be set up for failure. Without data I do believe the DNP is the bridge between research and translation to practice. I do not think DNP graduates are prepared to conduct original research." 
Other participants also cited age as a factor to consider when promoting the DNP degree, writing comments such as "Okay to have a doctorate, but too late in my career to do this."

\section{Discussion}

The role stress, ambiguity, and strain framework pictured in Figure 1 demonstrates that role stress leads to role ambiguity and role ambiguity leads to role strain, indicating goal attainment is impeded by both role strain and ambiguity. The complex relationship among role stress, ambiguity, and strain is presented in various directions and connections in the role perception literature. However, it is clear that role ambiguity poses a particularly detrimental threat to the nursing professionn. ${ }^{[31]}$ Because of this, our team chose to focus the discussion on the areas of role stress and strain, with the goal of preventing role ambiguity altogether.

This report of the qualitative findings complements and in forms the framework and quantitative results presented in Udlis and Mancuso ${ }^{[19]}$ and supports the recent findings of cost, program confusion, and lack of clarity in the faculty role reported by Dreifuerst and colleagues. ${ }^{[2]}$ Participants valued the DNP prepared nurse to advance healthcare outcomes through nursing leadership, policy, evidence-based practice and interprofessional collaboration. ${ }^{[19]}$ However, when given the opportunity to comment in their own words, many nurses frequently addressed areas of role stress, ambiguity, and strain. This shed light on areas of concern where further education or intervention are needed (see Table 1) providing the foundation for a discussion framed with solutions, rather than causing further turmoil and confusion among the nursing profession.

\subsection{Role stress}

Concerns regarding DNP degree academic preparation, program rigor and variability, the benefit of a DNP degree, and the entry into practice debate appeared to be a great source of role stress for the study participants. The AACN set certain DNP degree objectives meant to strengthen the nursing profession and address identified needs in the healthcare environment. These objectives address areas of concern such as nursing faculty and leader shortages and achieving parity with the education of other healthcare professionals. The AACN objectives also address areas for improvement of patient quality and safety through evidence-based practice and translation. ${ }^{[36]}$ This vision has been valued and rapidly adopted by the nursing profession with a proliferation of DNP programs. However, a lack of a clear and/or unified understanding of the degree and the educational preparation for the degree has contributed to areas of role stress.

Various nursing organizations have published documents and white papers with the intention to bring unity and clarity to the DNP degree. The National Organization of Nurse Practitioner Faculties (NONPF) published their perspective of DNP nurse practitioner (NP) preparation and made clear that NP preparation needs to be seamless and consistent in terms of competencies, clinical hours, and the consistent naming of culminating project to "DNP Project" to facilitate the DNP as the entry level degree to the NP role. ${ }^{[11]}$ AACN has addressed and clarified issues of curricular and practice expectations by convening a DNP Implementation Task Force. The Task Force published recommendations to describe and clarify the characteristics of DNP graduate scholarship, the DNP project, efficient use of resources, program length, curriculum considerations, practice experiences, and collaborative partnership guidelines. ${ }^{[4]}$

Schools of nursing should unite in assuring that DNP education takes a harmonious and consistent approach to educational preparation of a DNP prepared nurse. ${ }^{[1,4,36]}$ This does not imply that all DNP programs should be the same in structure or focus (i.e. policy, population health, executive leadership, etc.). The operationalization of the DNP Essentials has varied across DNP programs. All DNP programs should encompass a core set of competencies, as outlined in the DNP Essentials, which prepare graduates to improve health outcomes whether it be in the areas of patient, population, and/or policy. Review and accreditation processes for programs offering a DNP degree must uphold these core standards, but also be flexible to allow programs to develop curricula that meet the needs of their communities of interest.

The benefits of obtaining a DNP degree need to be widely communicated to those who are entering graduate education, as well as to the profession as a whole, the public, and other healthcare professionals. Likewise, future research should investigate the contributions and value of the DNP degree. ${ }^{[7,12,25]}$ Graduates from DNP programs should be prepared to fully articulate their distinct contributions to the nursing profession and encouraged to disseminate their accomplishments in various forms.

Efforts to unify nursing's voice regarding the DNP degree and DNP graduate will evolve over time. Discourse and opposition are both valuable tools that contribute to the process of growth and understanding of a new concept. This discourse and opposition has been well articulated in the area of the DNP graduate assuming roles in academia. Additional education and preparation for educator roles are recommended for the DNP graduate who wishes to assume faculty positions (this recommendation is also made for the $\mathrm{PhD}$ graduate).$^{[1,2,4]}$ Even though the intended outcome of the DNP degree has been consistently stated to develop prac- 
tice experts and not experts in academia, academic roles for DNP prepared nurses can greatly enhance the educational setting with the knowledge and skills of practice experts and the contributions of practice scholarship. The academic preparation of the DNP nurse remains a practice focus, and not an academic focus. AACN has recently restated their original stance that the, "discipline of education is....not an area of advanced nursing practice" and that the sole focus on preparation as nurse educators is incongruent with the intended outcomes of the DNP degree. ${ }^{[4]}$ Yet, 50\% of DNP students and $46 \%$ of DNP graduates reported their intention to become nurse educators when starting their doctoral program. ${ }^{[2]}$ Moreover, discourse regarding an education-focused DNP curriculum continues anecdotally and in the literature. For example, Danzey et al. ${ }^{[37]}$ and O'Lynn ${ }^{[38]}$ have advocated for programs that prepare the DNP educator for roles as faculty as well as academic leadership and administration with the ability of the DNP educator to advance scholarship. This type of debate regarding roles and expectations has been instrumental in moving the nursing profession forward through the years. However, given the past and current recommendations and statements from AACN, it is prudent to consider the potential harms (role stress) of ongoing debate versus the potential benefits. These conversations may be more productive once the level of role stress has reduced.

\subsection{Role strain}

Role strain resonated in the areas of degree competition, competition between the DNP and the $\mathrm{PhD}$, and competition between the DNP and the MSN. We believe these concerns regarding the "place" that the DNP takes within the nursing profession stem from the lack of understanding about the degree and the variability of the DNP preparation. According to the framework (see Figure 1), strategies to prevent role stress and ambiguity should prevent or reduce role strain.

While much has been written in the literature regarding $\mathrm{DNP} / \mathrm{PhD}$ differentiation and similarities, the issues surrounding DNP/MSN role ambiguity need further examination, especially in the area of the advanced practice registered nurse (APRN). Currently, it may appear that a MSN prepared APRN functions in the clinical setting just as a DNP prepared APRN does, however; healthcare is rapidly changing. DNP preparation has a greater emphasis on leadership, policy, population health, and quality improvement that can provide the APRN with a greater depth of knowledge and preparation to lead change beyond direct patient care competencies. Courses in informatics, translational research, quality improvement methods, health policy, and leadership expand the breadth of education allowing DNP graduates to step beyond individual direct care roles and assume greater

Published by Sciedu Press leadership, responsibility, and accountability for change to advance quality improvement, healthcare delivery, and clinical scholarship. ${ }^{[39]}$ The roles for the DNP prepared nurse are currently evolving and we are seeing examples of DNP prepared nurses having greater influence in the changes taking place in the delivery of healthcare, translating evidence into practice, and upholding best practices in nursing care. However, MSN prepared APRNs have much to contribute to the improvements in patient care.

While there is a dearth of literature regarding DNP and MSN collaboration, several studies have addressed the benefits of $\mathrm{DNP}$ and $\mathrm{PhD}$ prepared nurses working together to improve health outcomes. ${ }^{[13,17,40,41]}$ However, without a clear understanding of each other's contribution to the team, divergence will materialize, regardless of degree level. There should not be competition or a feeling of inferiority among the MSN, DNP, and PhD prepared nurse. "Intraprofessional" collaborative practice is the key to bringing harmony and reducing role strain in order to meet the goal of safe, high quality, accessible, and patient-centered care for improved patient and population outcomes. Such collaboration can be guided by the Core Competencies developed by the Interprofessional Education Collaborative (IPEC). ${ }^{[21]}$ IPEC outlines four competencies that guide interprofessional collaborative practice: values and ethics for interprofessional practice, roles/responsibilities, interprofessional communication, and teams and teamwork. These competencies (see Table 2) can be used as strategies to reduce role strain among all levels of nursing and should be integrated into all nursing curricula, not only to emphasize the need for interprofessional collaboration, but to help reduce the role strain intraprofessionally.

Collaborative relationships among DNP and PhD nurses are appearing in the literature. However, there needs to be networking and collaboration among MSN and DNP prepared nurses, as each has much to offer in terms of leadership, translating research into practice, and contributing to scholarship. With the slow, but steady, transition from MSN to DNP programs for advanced nursing practice, many well-educated and highly skilled MSN prepared nurses will continue to enter the nursing workforce. Partnerships between all levels of nursing, including our BSN colleagues, must be valued and nurtured as all members of the nursing profession have distinct knowledge and skills to contribute to the team.

\subsection{Limitations}

There are limitations within this study. Although comments and open-ended questions do address salient concepts, there was no opportunity to follow up with the participants to further probe or ask for clarification. The comments are a snap shot of what the nurses felt was most important to share after 
completing the survey. There is also the limitation that only those that felt most passionately about the DNP degree took the time to write in comments and therefore the findings are skewed in this way and exclude those who feel neutrality towards the DNP degree. Another limitation is the sample size, specifically the number of DNP comments $(8 \%)$ included in the analysis. Less than half $(33 \%)$ of the quantitative ques- tionnaires had participant comments. Although the sample size breakdown is similar to the original quantitative breakdown, including more DNP comments about their role would have benefitted analysis. Lastly, sample bias may be an issue as the sample was obtained in the Midwest. Nurses from other parts of the country may have an entirely different view regarding the DNP degree and role.

Table 2. Using IPEC competencies to reduce role strain*

\begin{tabular}{ll}
\hline IPEC Competency & Specific Competencies to Reduce Role Strain \\
\hline Values/Ethics for Interprofessional Practice & - Embrace individual differences \\
& - Respect the unique roles/responsibilities that characterize the nursing team \\
& - Communicate roles and responsibilities clearly \\
Roles/Responsibilities & - Recognize differences in skills and knowledge and use the combined knowledge \\
& to strengthen the team \\
& - Communicate effectively \\
- Anterprofessional Communication & - Encourage ideas and opinions from others \\
& - Foster nursing collaboration \\
Teams and Teamwork & - Develop consensus \\
& - Integrate each member's knowledge and experience \\
& - Share accountability \\
\hline
\end{tabular}

$*(\text { IPEC }=\text { Interprofessional Education Collaborative })^{[21]}$

\section{Conclusion}

The DNP degree is emerging quickly and as with any change comes uncertainty and confusion. This study identified several elements which are prevalent among nurses and identified in the literature that foster role stress and strain relating to the DNP prepared nurse. The identification of these key elements that contribute to role stress and role strain can assist academic institutions, healthcare and nursing organizations, and the profession as a whole to recognize the presence of stress and strain and to adopt tailored interventions and strategies to reduce them. These strategies may include a unified vision among the nursing profession regarding the DNP degree, a consistent core approach among schools of nursing in terms of program and curriculum, education of the profession, public, and other health professionals, and intraprofessional collaboration within the discipline, across all academic levels.

There is much to gain with the introduction of a practice doctorate in nursing. The DNP prepares nurses for leadership roles in a practice or systems focus making them ideal candidates to orchestrate change from the ground up in the health system, academic, and policy making arenas with the ultimate goal of improving the patient experience of care (including quality and satisfaction); improving the health of populations; and reducing the per capita cost of health care. From its inception, the DNP degree was designed to further meet the needs of the complex and rapidly changing healthcare environment. The profession has again evolved and with that evolution has come the expected stress, ambiguity, and strain that accompanies changes in organizations. The amount, duration, and severity of this stress, ambiguity, and strain will depend upon the nursing profession's ability to unite and work together to move our profession forward.

\section{Conflicts of InTEREST Disclosure}

The authors declare that there are no conflicts of interest.

\section{REFERENCES}

[1] American Association of Colleges of Nursing. The Essentials of Doctoral Education for Advanced Nursing Practice. 2006. Available from: http://www.aacn.nche.edu/publications/pos
ition/DNPEssentials.pdf

[2] Dreifuerst KT, McNelis AM, Weaver MT, et al. Exploring the pursuit of doctoral education by nurses seeking or intending to stay in faculty roles. J Prof Nurs. 2016; 32(3): 202-212. PMid: 27216128 
http://dx.doi.org/10.1016/j.profnurs

[3] Hudacek S, Carpenter DR. On doctoral education in nursing: The voice of the student. New York (NY): National League for Nursing Press; 1996.

[4] American Association of Colleges of Nursing. The Doctor of Nursing Practice: Current Issues and Clarifying Recommendations. 2015. Available from: http://www.aacn.nche.edu/aacn-publications/whit e-papers/DNP-Implementation-TF-Report-8-15.pdf

[5] McArthur DB. The journey to the doctor of nursing practice degree. In K Moran, R Burson, D Conrad (Eds.), The doctor of nursing practice scholarly project: A framework for success. Burlington (MA): Jones \& Bartlett; 2014. 15-32 pp.

[6] Udlis KA, Mancuso JM. Doctor of nursing practice programs across the United States: A benchmark of information part I: Program characteristics. J Prof Nurs. 2012; 28(5): 265-273. PMid: 23006648 http://dx.doi.org/10.1016/j.profnurs.2012.01.003

[7] Auerbach DI, Martsolf G, Pearson ML, et al. The DNP by 2015: A study of the institutional, political, and professional issues that facilitate or impede establishing a post-baccalaureate doctor of nursing practice program. 2014. Available from: http://www . aacn.nche. edu/dnp/DNP-Study . pdf

[8] Martsolf GR, Auerbach DI, Spetz J, et al. Doctor of nursing practice by 2015: An examination of nursing schools' decisions to offer a doctor of nursing practice degree. Nurs Outlook. 2015; 63(2): 219226. PMid: 25771195 http://dx.doi.org/10.1016/j.outlo ok.2015.01.002

[9] American Association of Colleges of Nursing. AACN Position Statement of the Practice Doctorate in Nursing. 2004. Available from: http://www.aacn.nche.edu/publications/positio n/DNPpositionstatement.pdf

[10] Melnyk BM. Distinguishing the preparation and roles of doctor of philosophy and doctor of nursing practice graduates: National implications of academic curricula and health care systems. J Nurs Educ. 2013; 52(8): 442-448. PMid: 23875724 http://dx.doi/10.3928 /01484834-20130719-01

[11] National Organization of Nurse Practitioner Faculties. The Doctorate of Nursing Practice NP Preparation: NONPF Perspective 2015. Available from: http://c.ymcdn.com/sites/www.nonpf .org/ resource/resmgr/DNP/NONPFDNPStatementSept2015.pdf? hhSearchTerms $=\% 22 \mathrm{DNP}+$ and $+2015 \% 22$

[12] Redman RW, Pressler SJ, Furspan P, et al. Nurses in the United States with a practice doctorate: Implications for leading in the current context of health care. Nurs Outlook. 2015; 63(2): 1214-129. PMid 25241137 http://dx.doi.org/10.1016/j.outlook.2014.08 .003

[13] Edwardson SR. Doctor of philosophy and doctor of nursing practice as complementary degrees. J Prof Nurs. 2010; 26(3): 137-140. PMid: $20488422 \mathrm{http}: / / \mathrm{dx}$.doi.org/10.1016/j.profnurs

[14] Ponte PR, Nicholas PK. Addressing the confusion related to DNS, DNsc, and DSN degrees, with lessons for the nursing profession. J Nurs Scholarsh. 2015; 47(4): 347-353. PMid: 26078101 http: $/ / \mathrm{dx}$.doi.org/10.1111/jnu. 12148

[15] Buchholz SW, Yingling C, Jones K, et al. DNP and PhD collaboration: Bringing together practice and research expertise as predegree and postdegree scholars. Nurse Educ. 2015; 40(4): 203-206. PMid: 25689076 http://dx.doi.org/10.1097/NNE. 0000000000000 141

[16] Moore K. How DNP and PhD nurses can collaborate to maximize patient care. American Nurse Today. 2014; 9(1): 48-49.

[17] Murphy MP, Staffileno BA, Carlson E. Collaboration among DNP and $\mathrm{PhD}$-prepared nurses: Opportunity to drive positive change. $\mathrm{J}$
Prof Nurs. 2015; 31(5): 388-394. PMid: 26428343 http: //dx.doi . org/10.1016/j.profnurs. 2015.03.001

[18] Glasgow ME, Zoucha R. Role strain in the doctorally prepared advanced practice nurse. In HM Dreher, ME Glasgow, Role development for doctoral advanced nursing practice. New York, (NY): Springer; 2011. 213-226 pp.

[19] Udlis KA, Mancuso JM. Perceptions of the role of the doctor of nursing practice-prepared nurse: Clarity or Confusion. J. Prof Nurs. 2015; 31(4): 274-283. PMid: 26194957 http://dx.doi .org/10. 1016/j.profnurs. 2015.01.004

[20] Ward-Smith P, Peterson JA, Kimble S. Student nurse perception of doctoral graduate programs. J Nurs Educ Practice. 2014; 4(5): 36-41.

[21] Interprofessional Education Collaborative Expert Panel. Core Competencies for Interprofessional Collaborative Practice: Report of an expert panel. 2011. Available from: http://www. aacn.nche.ed u/education-resources/ipecreport.pdf

[22] Swanson ML, Stanton M. Chief nursing officers' perceptions of the doctorate of nursing practice degree. Nurs Forum. 2013; 48(1): 35-44. PMid: 23379394 http://dx.doi.org/10.1111/nuf.12003

[23] Nichols C, O'Connor N, Dunn D. Exploring early and future use of DNP prepared nurses within healthcare organizations. J Nurs Adm. 2014; 44: 74-78. PMid: 24451444 http://dx.doi.org/10.1097 /NNA. 0000000000000029

[24] Swider SM, Levin P, Cowell J, et al. Community/public health nursing practice leaders' views of the doctorate of nursing practice. Public Health Nurs. 2009; 26(5): 405-411. PMid: 19706123 http://dx.doi.org/10.1111/j.1525-1446.2009.00798.x

[25] Cronenwett L, Dracup K, Grey M, et al. The doctor of nursing practice: A national workforce perspective. Nurs Outlook. 2011; 59(1): 9-17. PMid: $21741062 \mathrm{http}: / / \mathrm{dx}$.doi.org/10.1016/j.outlo ok. 2010.11.003

[26] Aselton P, Joerg K, Affenito S. Finding the middle ground - Adopting the doctor of nursing practice (DNP) for nurse practitioner education as a post-masters program while leaving master's level education intact. Clinical Nursing Studies. 2013; 1(1): 51-55. http: //dx.doi.org/10.5430/cns.v1n1p51

[27] Lenz E, Mundinger M, Kane R, et al. Primary care outcomes in patients treated by nurse practitioners or physicians: Two-year followup. Med Care Res Rev. 2004; 61(3): 332-351. PMid: 15358970 http://dx.doi.org/10.1177/1077558704266821

[28] Newhouse R, et al. Advanced practice nurse outcomes 1990-2008: A systematic review. Nurs Econ. 2011; 29(5): 1-21. PMid: 22372080

[29] Rizzo JR, House RJ, Lirtzman SI. Role conflict and ambiguity in complex organizations. Administrative Science Quarterly. 1970; 5: 150163. Available from: http://cyb.ox.or.kr/lms_board/bbs_u pload $/ \%$ C $1 \%$ F $7 \%$ B9 $\% A B \% B D \% B A \% 6 \% A E \% B 7 \% B 9 \% B D \% B 2$.pdf

[30] Hardy ME, Conway ME. Role theory: Perspectives for health professionals (2nd ed.). Norwalk, (CT): Appleton \& Lange; 1988.

[31] Hardy ME, Hardy WL. Role stress and role strain. In ME Hardy, ME Conway, Role theory: Perspectives for health professionals (2nd ed.). Norwalk, (CT): Appleton \& Lange; 1988. 159-239 pp.

[32] Fink A. How to conduct surveys: A step-by-step guide (4th ed.) Thousand Oaks, (CA): Sage Publications; 2008.

[33] Geer J G. Do open-ended questions measure "salient" issues? Public Opinion Quarterly. 1991; 55(3): 360-370. Available from: http: //poq.oxfordjournals.org/content/55/3/360. short

[34] Elo S, Kyngäs H. The qualitative content analysis process. J Adv Nurs. 2008; 62(1): 107-115. PMid: 18552969 http://dx.doi.o $\mathrm{rg} / 10.1111 / \mathrm{j} \cdot 1365-2648.2007 .04569 \cdot \mathrm{x}$

[35] Vaismoradi M, Turunen H, Bondas T. Content analysis and thematic analysis: Implications for conducting a qualitative descriptive study: 
Qualitative descriptive study. Nurs Health Sci. 2013; 15(3): 398-405. PMid: 23480423 http: //dx.doi .org/10.1111/nhs. 12048

[36] American Association of Colleges of Nursing. DNP Roadmap Task Force Report. 2006. Available from: http://www. aacn.nche.ed u/dnp/roadmapreport.pdf

[37] Danzey IM, Emerson EA, Fitzpatrick JJ, et al. The doctor of nursing practice and nursing education: Highlights, potential, and promise. J Prof Nurs. 2011; 27(5): 311-314. PMid: 21925464 http://dx.doi.org/10.1016/j.profnurs.2011.06.008

[38] O'Lynn C. Endorsing the doctor of nursing practice pathway for nurse educators. J Nurs Educ. 2015; 54(9): 475-477. PMid: 26334332 http://dx.doi.org/10.3928/01484834-20150814-10
[39] Mundinger MO. Who's who in nursing: bringing clarity to the doctor of nursing practice. Nurs Outlook. 2005; 53(4): 173-176. PMid: 16115508 http://dx.doi.org/10.1016/j.outlook.2005.05 .007

[40] Beverly CJ. Changing health care environment: Getting beyond the PhD versus DNP discussion. J Prof Nurs. 2014; 30(2): 101102. PMid: 24720937 http://dx.doi.org/10.1016/j.profn urs.2014.02.003

[41] Clinton P, Sperhac AM. The DNP and unintended consequences: An opportunity for dialogue. J Pediatr Health Care. 2009; 23(5): 348351. PMid $19720272 \mathrm{http}: / / \mathrm{dx}$.doi.org/10.1016/j.pedhc. 2 009.06 .004 